\title{
Endometriosis involving the mucosa of the intestinal tract: a clinicopathologic study of 15 cases
}

\author{
Wei Jiang*,1, Andres A Roma ${ }^{1}$, Keith Lai ${ }^{1}$, Paula Carver ${ }^{1}$, Shu-Yuan Xiao ${ }^{2}$ and \\ Xiuli Liu ${ }^{1}$ \\ ${ }^{1}$ Department of Anatomic Pathology, Cleveland Clinic, Cleveland, OH, USA and ${ }^{2}$ Department of \\ Pathology, University of Chicago, Chicago, IL, USA
}

\begin{abstract}
Endometriosis involving the mucosa of the intestines is rare, but may lead to diagnostic pitfalls. We reviewed 15 cases (seven biopsies and eight resections) from 14 patients. The patients' mean age is 48 years (31-66 years). Presenting symptoms included lower gastrointestinal bleeding, pelvic pain, rectal urgency, abdominal mass, and bowel obstruction. In the majority of cases, the lesion was located in the rectum $(73 \%)$ with the remainder in the sigmoid colon $(20 \%)$ and ileum $(7 \%)$. The most common indication for biopsy was a polypoid lesion seen endoscopically (eight cases). For patients who underwent resections, the most common clinical impression was colonic carcinoma $(75 \%)$, due to mass lesions and stricture as the most common macroscopic findings. Histologically, one case had stromal endometriosis only, but the remaining 14 cases had both endometrial glands and stroma. Epithelial metaplasia was present in all cases, mostly tubal metaplasia (ciliated epithelium). Hybrid glands and replacement of the surface epithelium by endometrial epithelium were also seen. Crypt architectural distortion, cryptitis, and crypt abscesses were seen in some cases, mimicking chronic active colitis or enteritis. A panel of immunohistochemical stains (CK7, CK20, CDX2, and ER) was found to be useful in biopsies with suspected endometriosis demonstrating unusual histology or only containing endometrioid stroma tissue. Vascular involvement by endometriosis was identified in one case. Endometrial hyperplasia $(n=2)$ and cancer $(n=1)$ were also seen in the ectopic tissue. All patients were alive at follow-up (3-216 months, mean 67 months). Modern Pathology (2013) 26, 1270-1278; doi:10.1038/modpathol.2013.51; published online 12 April 2013
\end{abstract}

Keywords: cytokeratin 7; endometriosis; estrogen receptor; intestine; polypoid endometriosis; stromal endometriosis

The common female disease endometriosis involves many sites, one being the gastrointestinal tract, which is involved in $3.8-37 \%$ of patients. ${ }^{1-4}$ The most common location in the gastrointestinal tract is the sigmoid colon and rectum, followed by ileum, appendix, and cecum. ${ }^{4}$ Although most patients with intestinal endometriosis have only mild symptoms, severe complications such as gastrointestinal tract bleeding, bowel obstruction, and perforation can occur. ${ }^{5-11}$ Endoscopic and imaging findings may mimic other diseases including colitis, ${ }^{12}$ idiopathic

Correspondence: Dr X Liu, MD, PhD, Department of Anatomic Pathology, Cleveland Clinic, 9500 Euclid Avenue/L25, Cleveland, $\mathrm{OH} 44195$, USA.

E-mail: liux3@ccf.org

${ }^{*}$ Current address: Department of Pathology, Thomas Jefferson University, Philadelphia, PA, USA.

Received 14 December 2012; revised 14 January 2013;

accepted 14 January 2013; published online 12 April 2013 inflammatory bowel disease, ${ }^{13}$ solitary rectal ulcer syndrome, ${ }^{14}$ colorectal adenoma, and cancer. $^{15}$ Therefore, it remains a diagnostic challenge clinically. ${ }^{16}$

Diagnosing intestinal endometriosis in the bowel wall, involving the serosa, muscularis propria, and/ or submucosa, is usually straightforward in resection specimens. ${ }^{16,17}$ The presence of endometrial glands, endometrial stroma, and hemosiderin deposition, often referred to as 'diagnostic triad', is present in most cases. When endometriosis involves the intestinal mucosa, it may cause diagnostic difficulty, especially in endoscopic biopsies. This phenomenon has not been well-studied, and large series are lacking in the literature. We report a retrospective review of 15 cases from 14 patients with endometriosis involving the intestinal mucosa, including seven biopsies and eight resections. We analyze the clinicopathologic characteristics and report the clinical outcomes of these cases. 


\section{Materials and methods}

\section{Patients}

This study was approved by the Institutional Review Board. The surgical pathology database at Cleveland Clinic (1994-2011) was searched for intestinal endometriosis, and only those with mucosal involvement by endometriosis were included. There were a total of 15 cases from 14 patients.

\section{Histology and Immunohistochemistry}

The H\&E slides and immunohistochemical stains were reviewed by two gastrointestinal pathologists (XL and WJ), and one gynecologic pathologist (AAR). Immunohistochemical stains were performed using the following antibodies: CK7 (M7018, Dako, Capertina, CA, USA, 1:40 dilution), CK20 (M7019, Dako, 1:20 dilution), ER (SP1, Ventana, Tucson, AZ, USA, prediluted), CD10 (56C6, Novocastra, Buffalo Grove, IL, USA, 1:5 dilution), WT1 (6FH2, Dako, 1:100 dilution), CD34 (QBend/10, Cell Marque, Rocklin, CA, USA, prediluted), S-100 (polyclonal, Dako, 1:200 dilution), calretinin (polyclonal, Invitrogen, Grand Island, NY, USA, 1:40 dilution), smooth muscle actin (1A4, Dako, 1:50 dilution), CDX2 (CDX2-88, Biogenex, Fremont CA, USA, 1:4 dilution), and CD117 (polyclonal, Dako, 1:200 dilution).

For double antibody staining, immunohistochemistry was performed on $4 \mu \mathrm{m}$ sections of formalin or Hollandes-fixed, paraffin-embedded tissue using a Discovery XT automated stainer (Ventana Medical Systems). For ER/CK7, the primary antibodies are: ER (polyclonal, 790-4325, Ventana, prediluted) and CK7 (M7018, Dako, 1:40 dilution). Secondary antibody OmniMap anti-Rabbit horseradish peroxidase (HRP) (Ventana) was applied for ER antibody, and UltraMap anti-Mouse alkaline phosphatase antibody (Ventana) was used for CK7. For CDX2/CK20, mouse monoclonal antibodies CDX2 (MU392-A-UC, Biogenex, 1:10 dilution) and CK20 (M7019, Dako, 1:20 dilution) were used. Secondary antibody OmniMap was applied for CDX2 antibody, and UltraMap was used for CK20. The chromogenic substrates (ChromoMap DAB and ChromoMap RED, Ventana) were applied, and slides were counterstained with Hematoxylin II post counterstaining with Bluing Reagent (Ventana), and visualized by light microscopy.

\section{Results}

\section{Clinical Presentation, Endoscopic and Macroscopic Findings}

The clinical characteristics and macroscopic findings of the 15 cases (seven biopsies and eight resections) are summarized in Table 1 . Patient age ranged from 31 to 66 years (mean, 48 years). Nine patients $(64.3 \%)$ had no prior history of endometriosis, whereas five had known history of the disease involving vagina, fallopian tube, ovary, and colorectum. Two patients were taking oral contraceptives, and two others were on unopposed estrogen therapy. Presenting symptoms included lower gastrointestinal bleeding $(n=5)$, pelvic or abdominal pain $(n=3)$, rectal urgency $(n=1)$, diarrhea $(n=1)$, change in bowel habits $(n=1)$, severe generalized weakness $(n=1)$, abdominal mass $(n=1)$, and bowel obstruction $(n=1)$. Eleven cases were located within the rectum $(73 \%)$, three within the sigmoid colon $(20 \%)$, and one $(7 \%)$ within the ileum.

Endoscopy reports $(n=6)$ were available for six biopsied cases, which revealed polypoid lesions, ranging from small sessile polyp to large pedunculated or sessile non-bleeding polyp $(0.7-1.5 \mathrm{~cm})$. The clinical impressions in these cases included colonic polyp/adenoma $(n=3)$, solitary rectal ulcer syndrome $(n=1)$, and rule out colorectal carcinoma $(n=1)$. In one patient with established Crohn's disease status post ileocolic resection, a sessile, non-bleeding $1.5-\mathrm{cm}$ polyp was identified originally in the rectum (case 5), and there was a clinical suspicion for colonic adenoma. Review of the patient's prior biopsy specimens showed classic patchy chronic active colitis with rare well-formed mucosal granulomas consistent with Crohn's disease.

In patients who underwent resections $(n=8)$, mass lesions were the most common gross finding $(n=6$, Table 1), ranging from 1 to $5 \mathrm{~cm}$ in size, and appeared polypoid or transmural. One patient had two polypoid masses $(2.6 \mathrm{~cm}$ serosal and $3.2 \mathrm{~cm}$ mucosal) in addition to a pelvic polypoid mass $(2.7 \mathrm{~cm})$. Grossly, the masses were red/tan to brown with a tanned, cut surface demonstrating cystic change. Hemorrhagic foci were also present. The remaining two cases showed severe stricture with near-complete obstruction caused by colonic wall thickening, ranging from 1.2 to $1.6 \mathrm{~cm}$ in wall thickness. The most common clinical impression in these patients was colonic carcinoma $(n=6)$, and in one patient, MRI showed a $3.5-\mathrm{cm}$ mass with loss of fat plane between the mass, cervix, and vagina, and a T4 rectal cancer was suspected preoperatively. Endometriosis was only suspected in one patient with known history $(n=1)$.

\section{Microscopic Findings}

All cases had mucosal involvement by endometriosis. In the seven biopsy specimens, one also had submucosal involvement. In the resected cases, 5 contained transmural involvement from mucosa to subserosal soft tissue, with one case showing adhesion to the cervix. Three cases showed mucosa/submucosa/muscularis propria involvement. A summary of the histopathologic findings seen in these cases is presented in Table 2. 
Table 1 Clinical, demographic and macroscopic findings

\begin{tabular}{|c|c|c|c|c|c|c|c|c|c|c|}
\hline Case & Tyре & Age & Site & Other Dxs & Symptoms & $H / O E M$ & Estrogen $R x$ & Gross/Endo & Clinical Dx & $F / U$ (month) \\
\hline 1 & $\mathrm{Bx}$ & 54 & Rectum & & N/A & Y(vagina) & $\mathrm{Y}$ & N/A & R/O carcinoma & 216 (alive) \\
\hline 2 & $\mathrm{Bx}$ & 54 & Rectum & & $\begin{array}{l}\text { Severe } \\
\text { generalized } \\
\text { weakness }\end{array}$ & $\mathrm{N}$ & N/A & $\begin{array}{l}\text { Large } \\
\text { pedunculated } \\
\text { polyp }\end{array}$ & $\begin{array}{l}\text { SRUS w/ thick } \\
\text { folds }\end{array}$ & 156 (alive) \\
\hline 3 & $\mathrm{Bx}$ & 54 & Sigmoid & HCV & None & $\mathrm{N}$ & N/A & $\begin{array}{l}\text { 7-mm sessile } \\
\text { polyp }\end{array}$ & Adenoma & 63 (alive) \\
\hline 4 & $\mathrm{Bx}$ & 45 & Rectum & & $\begin{array}{l}\text { Rectal } \\
\text { bleeding }\end{array}$ & $\mathrm{N}$ & $\mathrm{N}$ & $\begin{array}{l}\text { Erythema } \\
\text { polypoid lesion }\end{array}$ & R/O EM & 19 (alive) \\
\hline 5 & $\mathrm{Bx}$ & 31 & Rectum & $\mathrm{CD}$ & $\begin{array}{l}\text { Chronic } \\
\text { abdominal } \\
\text { pain }\end{array}$ & $\mathrm{N}$ & $\mathrm{Y}$ & $\begin{array}{l}\text { Sessile, non- } \\
\text { bleeding polyp } \\
1.5 \mathrm{~cm}\end{array}$ & $\begin{array}{l}\mathrm{CD}, \mathrm{R} / \mathrm{O} \\
\text { adenoma }\end{array}$ & 9 (alive) \\
\hline $6^{\mathrm{a}}$ & $\mathrm{Bx}$ & & Rectum & & & & & $\begin{array}{l}\text { Ileorectal fistula, } \\
\text { two rectal stump } \\
\text { polyps }\end{array}$ & EM & \\
\hline 7 & $\mathrm{Bx}$ & 45 & Rectum & & $\begin{array}{l}\text { Rectal } \\
\text { bleeding }\end{array}$ & $\mathrm{N}$ & N/A & Polyp & Colonic polyp & 3 (alive) \\
\hline 8 & Resec & 50 & Rectum & & N/A & Y (FT, ovary) & $\mathrm{N}$ & $\begin{array}{l}\text { Mass } \\
5 \times 4 \times 4 \mathrm{~cm}\end{array}$ & $\begin{array}{l}\text { Rectal } \\
\text { carcinoma }\end{array}$ & 88 (alive) \\
\hline 9 & Resec & 56 & Rectum & & $\begin{array}{l}\text { Lower GI } \\
\text { bleeding } \times 3 \\
\text { months }\end{array}$ & $\mathrm{N}$ & $\mathrm{N}$ & $\begin{array}{l}\text { 1-cm polypoid } \\
\text { mass-transmural }\end{array}$ & $\begin{array}{l}\text { Rectal } \\
\text { carcinoma }\end{array}$ & 173 (alive) \\
\hline 10 & Resec & 42 & Rectum & & $\begin{array}{l}\text { Pelvic pain, } \\
\text { rectal urgency }\end{array}$ & $\mathrm{Y}$ & OCP & $\begin{array}{l}\text { Near-obstructing } \\
\text { mass (endo), } \\
\text { thickened bowel } \\
\text { wall ( } 3.2 \mathrm{~cm} \text { in } \\
\text { length, } 1.6 \mathrm{~cm} \text { in } \\
\text { thickness) }\end{array}$ & $\begin{array}{l}\text { Rectal } \\
\text { carcinoma }\end{array}$ & 132 (alive) \\
\hline 11 & Resec & 41 & Sigmoid & & $\begin{array}{l}\text { Diarrhea, GI } \\
\text { bleed }\end{array}$ & $\mathrm{N}$ & $\mathrm{N}$ & $\begin{array}{l}\text { Complete } \\
\text { stricture }(3 \mathrm{~cm} \text { in } \\
\text { length, } 1.2 \mathrm{~cm} \\
\text { thickness) }\end{array}$ & Mass/stricture & 12 (alive) \\
\hline 12 & Resec & 49 & Rectum & EMC & $\begin{array}{l}\text { Change in } \\
\text { bowel } \\
\text { movements } \\
\times 6 \text { months }\end{array}$ & & $\mathrm{N}$ & $\begin{array}{l}3.5 \mathrm{~cm} \text { mass with } \\
\text { loss of fat plane } \\
\text { between the } \\
\text { mass, cervix, and } \\
\text { vagina (MRI), } \\
\text { puckered area } \\
\text { adhesed to cervix }\end{array}$ & Rectal cancer T4 & 26 (alive) \\
\hline 13 & Resec & 35 & Ileum & & Adnexal mass & $\mathrm{Y}$ & $\begin{array}{l}\text { Depo } \\
\text { Provera } \times 3 \text {; } \\
\text { OCP } \times 1 \text { year }\end{array}$ & $\begin{array}{l}\text { 4-cm protruding } \\
\text { serosal lesion }\end{array}$ & Pelvic mass/EM & 19 (alive) \\
\hline 14 & Resec & 66 & $\begin{array}{l}\text { Sigmoid/ } \\
\text { rectum }\end{array}$ & & $\begin{array}{l}\text { Distal bowel } \\
\text { obstruction }\end{array}$ & $\mathrm{N}$ & Megestrol & $\begin{array}{l}\text { 4-cm transmural } \\
\text { mass }\end{array}$ & & 14 (alive) \\
\hline 15 & Resec & 55 & Rectum & & $\begin{array}{l}\text { Severe rectal } \\
\text { pain/spasms, } \\
\text { rectal bleeding } \\
\times 2 \text { days }\end{array}$ & $\mathrm{Y}$ & $\mathrm{N}$ & $\begin{array}{l}\text { Two polypoid } \\
\text { masses }(2.6-\mathrm{cm} \\
\text { serosal, } 3.2-\mathrm{cm} \\
\text { mucosal) }\end{array}$ & $\begin{array}{l}\text { Colorectal EM, } \\
\text { s/p Hartmann, } \\
\text { anastomotic } \\
\text { leak, colo- } \\
\text { cutaneous } \\
\text { fistula }\end{array}$ & 13 (alive) \\
\hline
\end{tabular}

Abbreviations: Bx, biopsy; CD, Crohn's disease; Dx, diagnosis; EM, endometriosis; EMC, endometrioid adenocarcinoma; GI, gastrointestinal; HCV, hepatitis C virus infection; N/A, not available; OCP, oral contraceptive pill; Resec, resection; R/O, rule out; SRUS, solitary rectal ulcer syndrome.

${ }^{\mathrm{a}}$ Cases 5 and 6 are from the same patient 6 months apart.

In 14 cases, the lesion contained both endometrial glands and stroma. The glandular epithelia were cuboidal to columnar, with ovoid nuclei and an open chromatin pattern (Figures 1a and b). Epithelial metaplasia, a frequent finding in endometriosis, was present in all cases, with tubal metaplasia (ciliated epithelium) being the most common $(n=11)$ (Figure 1c), followed by squamous $(n=3)$ (Figure 1d), mucinous $(n=2)$, hobnail $(n=1)$, and eosinophilic metaplasia $(n=1)$. Hybrid glands con- sisting of endometrial and colonic epithelium were evident in seven cases (Figures 1e and f). All cases involved proliferative or inactive type of endometrial glands, with no secretory-type glands identified in any of the cases. In nine cases, the glands exhibited cystic dilatations, and were partially lined by flattened epithelium. The stroma was characterized by stromal cells, small blood vessels, and extravasated red blood cells (Figures 1a and c). Hemosiderin-laden macrophages were a frequent 
Table 2 Histopathologic findings

\begin{tabular}{|c|c|c|c|c|c|c|c|c|c|c|c|c|c|}
\hline \multicolumn{3}{|c|}{ Case Spec. Mural } & \multicolumn{5}{|c|}{ EM gland } & \multicolumn{5}{|c|}{ Mucosa } & \multirow[t]{2}{*}{ Final $D x$} \\
\hline & & & \multicolumn{2}{|c|}{ Type Meta. } & \multirow{2}{*}{$\frac{\text { Cyst }}{\mathrm{Y}}$} & \multirow{2}{*}{$\begin{array}{c}\begin{array}{c}\text { Replace } \\
\text { surface }\end{array} \\
\mathrm{N}\end{array}$} & \multirow{2}{*}{$\begin{array}{l}\text { Hyperp/Ca } \\
\text { СAH }\end{array}$} & \multirow{2}{*}{$\frac{\text { Activity }}{\mathrm{N}}$} & \multirow{2}{*}{$\begin{array}{c}\begin{array}{c}\text { Crypt } \\
\text { distort }\end{array} \\
\mathrm{Y}\end{array}$} & \multirow{2}{*}{$\begin{array}{l}\text { Eros/ } \\
\text { ulcer }\end{array}$} & \multirow{2}{*}{$\begin{array}{c}\begin{array}{c}\text { Vessels } \\
(*)\end{array} \\
\mathrm{N}\end{array}$} & \multirow[t]{2}{*}{ Hemo } & \\
\hline 1 & BX & $\mathrm{M}$ & $\mathrm{P}$ & Sq, cilia & & & & & & & & & $\begin{array}{l}\text { Ulcerated, } \\
\text { inflamed EM w/ } \\
\text { CAH }\end{array}$ \\
\hline 2 & $\mathrm{Bx}$ & M & $\mathrm{P}$ & Cilia & $\mathrm{N}$ & $\mathrm{N}$ & $\mathrm{N}$ & $\mathrm{N}$ & $\mathrm{Y}$ & $\mathrm{N}$ & $\mathrm{N}$ & $\mathrm{N}$ & $\mathrm{EM}$ \\
\hline 3 & $\mathrm{Bx}$ & $\mathrm{M} / \mathrm{SM}$ & N/A & $\mathrm{N}$ & $\mathrm{N}$ & $\mathrm{N}$ & $\mathrm{N}$ & $\mathrm{N}$ & $\mathrm{Y}$ & Eros & $\mathrm{Y}$ & $\mathrm{N}$ & Stromal EM \\
\hline 4 & $\mathrm{Bx}$ & M & $\mathrm{P}$ & Cilia & $\mathrm{N}$ & $\mathrm{Y}$ & $\mathrm{N}$ & $\mathrm{Y}$ & $\mathrm{Y}$ & $\mathrm{N}$ & $\mathrm{N}$ & Y 1 & EM \\
\hline 5 & $\mathrm{Bx}$ & $\mathrm{M}$ & $\mathrm{P}$ & Sq, cilia & $\mathrm{N}$ & $\mathrm{Y}$ & $\mathrm{N}$ & $\mathrm{Y}$ & $\mathrm{Y}$ & $\mathrm{N}$ & $\mathrm{Y}$ & Y & $\mathrm{EM}$ \\
\hline 6 & $\mathrm{Bx}$ & $\mathrm{M}$ & $\mathrm{P}$ & $\begin{array}{l}\text { Cilia, } \\
\text { hobnail }\end{array}$ & $\mathrm{N}$ & $\mathrm{Y}$ & $\mathrm{CAH}$ & $\mathrm{Y}$ & $\mathrm{Y}$ & Ulcer & $\mathrm{Y}$ & $\mathrm{Y}$ & $\mathrm{EM}$ w/ CAH \\
\hline 7 & $\mathrm{Bx}$ & $\mathrm{M}$ & $\mathrm{P}$ & Cilia & $\mathrm{N}$ & $\mathrm{Y}$ & $\mathrm{N}$ & $\mathrm{Y}$ & $\mathrm{Y}$ & Ulcer & $\mathrm{Y}$ & $\mathrm{N}$ & EM \\
\hline 8 & $\mathrm{R}$ & $\begin{array}{l}\mathrm{M} / \mathrm{SM} / \mathrm{MP} / \\
\mathrm{ST}\end{array}$ & $\mathrm{P}$ & Cilia & $\mathrm{Y}$ & $\mathrm{Y}$ & $\begin{array}{l}\text { CAH with } \\
\text { stromal } \\
\text { atypia }\end{array}$ & $\mathrm{Y}$ & $\mathrm{Y}$ & Eros & $\mathrm{Y}$ & $\mathrm{Y}$ & $\begin{array}{l}\text { EM w/ focal CAH \& } \\
\text { evolving LG } \\
\text { carcinosarc }\end{array}$ \\
\hline 9 & $\mathrm{R}$ & $\begin{array}{l}\mathrm{M} / \mathrm{SM} / \mathrm{MP} / \\
\mathrm{ST}\end{array}$ & $\mathrm{P}$ & Cilia & $\mathrm{Y}$ & $\mathrm{N}$ & $\mathrm{N}$ & $\mathrm{Y}$ & $\mathrm{Y}$ & Eros & $\mathrm{Y}$ & $\mathrm{N}$ & EM \\
\hline 10 & $\mathrm{R}$ & $\begin{array}{l}\mathrm{M} / \mathrm{SM} / \mathrm{MP} / \\
\mathrm{ST}\end{array}$ & $\mathrm{P}, \mathrm{I}$ & Mucin. & $\mathrm{Y}$ & $\mathrm{N}$ & $\mathrm{N}$ & $\mathrm{N}$ & $\mathrm{Y}$ & $\mathrm{N}$ & $\mathrm{N}$ & $\mathrm{N}$ & EM \\
\hline 11 & $\mathrm{R}$ & M/SM/MP & $\mathrm{P}$ & Cilia & $\mathrm{Y}$ & $\mathrm{N}$ & $\mathrm{N}$ & $\mathrm{N}$ & $\mathrm{Y}$ & $\mathrm{N}$ & $\mathrm{N}$ & $\mathrm{N}$ & EM \\
\hline 12 & $\mathrm{R}$ & $\mathrm{M} / \mathrm{SM} / \mathrm{MP}$ & $\mathrm{P}$ & Eosino. & $\mathrm{Y}$ & $\mathrm{Y}$ & $\mathrm{N}$ & $\mathrm{N}$ & $\mathrm{Y}$ & $\mathrm{N}$ & $\mathrm{N}$ & $\mathrm{N}$ & $\mathrm{EM}$ \\
\hline 13 & $\mathrm{R}$ & $\mathrm{M} / \mathrm{SM} / \mathrm{MP}$ & $\mathrm{P}$ & Cilia & $\mathrm{Y}$ & $\mathrm{N}$ & $\mathrm{N}$ & $\mathrm{N}$ & $\mathrm{Y}$ & $\mathrm{N}$ & $\mathrm{N}$ & $\mathrm{N}$ & EM \\
\hline 14 & $\mathrm{R}$ & $\begin{array}{l}\mathrm{M} / \mathrm{SM} / \mathrm{MP} / \\
\mathrm{ST}\end{array}$ & $\mathrm{P}$ & $\mathrm{Sq}$ & $\mathrm{Y}$ & $\mathrm{Y}$ & EMC & $\mathrm{N}$ & $\mathrm{Y}$ & $\mathrm{N}$ & $\mathrm{N}$ & $\mathrm{N}$ & EMC \\
\hline 15 & $\mathrm{R}$ & $\begin{array}{l}\mathrm{M} / \mathrm{SM} / \mathrm{MP} / \\
\mathrm{ST}\end{array}$ & $\mathrm{P}, \mathrm{I}$ & $\begin{array}{l}\text { Cilia, } \\
\text { mucin. }\end{array}$ & $\mathrm{Y}$ & $\mathrm{Y}$ & $\mathrm{N}$ & $\mathrm{Y}$ & $\mathrm{Y}$ & Eros & $\mathrm{Y}$ & $\mathrm{Y}$ & EM \\
\hline
\end{tabular}

Abbreviations: Bx, biopsy; Ca, cancer; carcinosarc, carcinosarcoma; CAH, complex atypical hyperplasia; Cilia, ciliated; Dx, diagnosis; EM, endometriosis; EMC, endometrioid adenocarcinoma; Eosino, eosinophilic; Eros, erosion; Hemo, hemorrhage; Hyperp, hyperplasia; I, inactive; LG, low grade; M, mucosa; Meta, metaplasia; MP, muscularis propria; mucin, mucinous; N, no vascular changes; P, proliferative; R, resection; SM, submucosa; Spec, specimen; Sq, squamous; ST, subserosal soft tissue; Vessels $\left.{ }^{*}\right)$-Y; thickened vessels with congestion.

finding (Figure 1b). The stroma usually cuffed around the endometrial glands. However, in some cases, it was paucicellular with edematous/myxoid changes, and not readily evident focally.

In eight cases (53\%), the surface colonic epithelium was also replaced by endometrial glandular epithelium (Figures $1 \mathrm{~g}$ and $\mathrm{h}$ ). In cases with endoscopic impression of polypoid lesions, the polyps consisted of mucosal endometriosis histologically (Figure 2a). In these cases, mucosal surface erosion/ulceration was present in seven cases. Crypt architectural distortion was present in all cases (Figure 2b). Seven cases also showed cryptitis and crypt abscesses. Prolapse changes including fibromuscular hyperplasia were present in three cases, some of which were caused by a submucosal endometriosis focus (Figure 2c). Vascular involvement by endometriosis was seen in one case (Figure 2d).

\section{Immunohistochemistry}

The diagnosis of endometriosis is usually straightforward based on the classic histomorphology, and generally requires no immunostains, especially on resection specimens. Out of our eight resection cases, only two required immunostains, one of which was for endometrioid adenocarcinoma (see below). On biopsy specimens, however, obtaining the correct diagnosis can be challenging, mostly due to limited amount of tissue present (one case contained only two endometrioid glands in the entire specimen), or confusion with colonic adenoma/low-grade dysplasia. In four biopsy cases, immunostains were performed to aid in the diagnosis.

In this series, we also performed dual immunostains utilizing antibodies directed against CK7/ER and CK20/CDX2 in all cases with tissue available $(n=11)$. The endometrial glands in all tested cases were positive for CK7 and ER, and negative for CK20 and CDX2, whereas the colonic epithelium had the opposite pattern, staining positively for CK20 and CDX2, but negatively for CK7 and ER.

Although the majority of endometriosis cases contain both glandular and stromal components, sometimes only endometrial-type stroma is present. The latter lesions are referred to as 'stromal endometriosis', and are thought to be most likely due to limited sampling. ${ }^{18}$ In our series, one biopsy case showed a cellular spindle cell proliferation within the lamina propria (Figures 2e and f). Immunostains demonstrated the spindle cells to be 

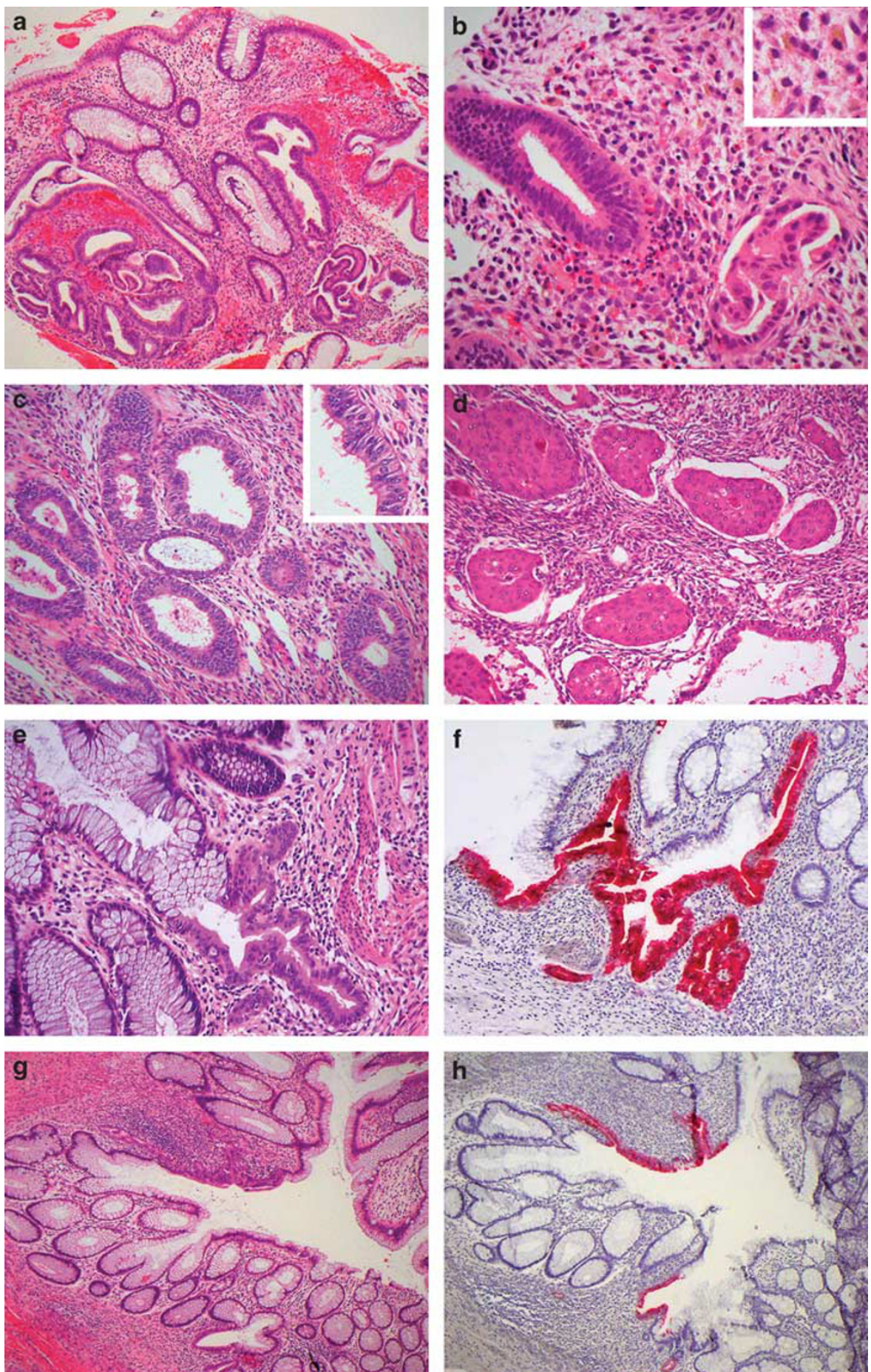

Figure 1 (a) Endometriosis involving colonic mucosa in a biopsy specimen. Endometrioid glands are surrounded by endometrial-type stroma with hemorrhage and edematous changes (H\&E, 40×). (b) Higher power view of (a), demonstrating hemosiderin-laden macrophages within the stroma (also see inset). The gland on the left is lined by columnar epithelium with pseudostratification and cilia $(\mathrm{H} \& \mathrm{E}, 200 \times)$. (c) Tubal (ciliated) metaplasia (also see inset) $(\mathrm{H} \& \mathrm{E}, 200 \times)$. (d) Squamous metaplasia $(\mathrm{H} \& \mathrm{E}, 200 \times)$. (e) Hybrid gland between colonic mucinous epithelium and endometrial-type epithelium (H\&E, $400 \times$ ). (f) Immunostain for CK7 (red) and ER (brown) confirms the presence of the hybrid gland (CK7/ER double immunoperoxidase stain, $40 \times$ ). (g) Replacement of surface epithelium by endometrial-type epithelium $(\mathrm{H} \& \mathrm{E}, 40 \times$ ). (h) The endometrial-type surface epithelium was highlighted by CK7 (red) and ER (brown) immunostains (CK7/ER double immunoperoxidase stain, 40X).

strongly positive for CD10 and ER, but negative for S-100, CD117, and CD34 (markers for schwannoma and gastrointestinal stromal tumor), confirming the diagnosis of stromal endometriosis.

\section{Neoplasia in Intestinal Endometriosis}

Similar to native endometrium, ectopic endometrial tissue can also develop hyperplasia, dysplasia, and 

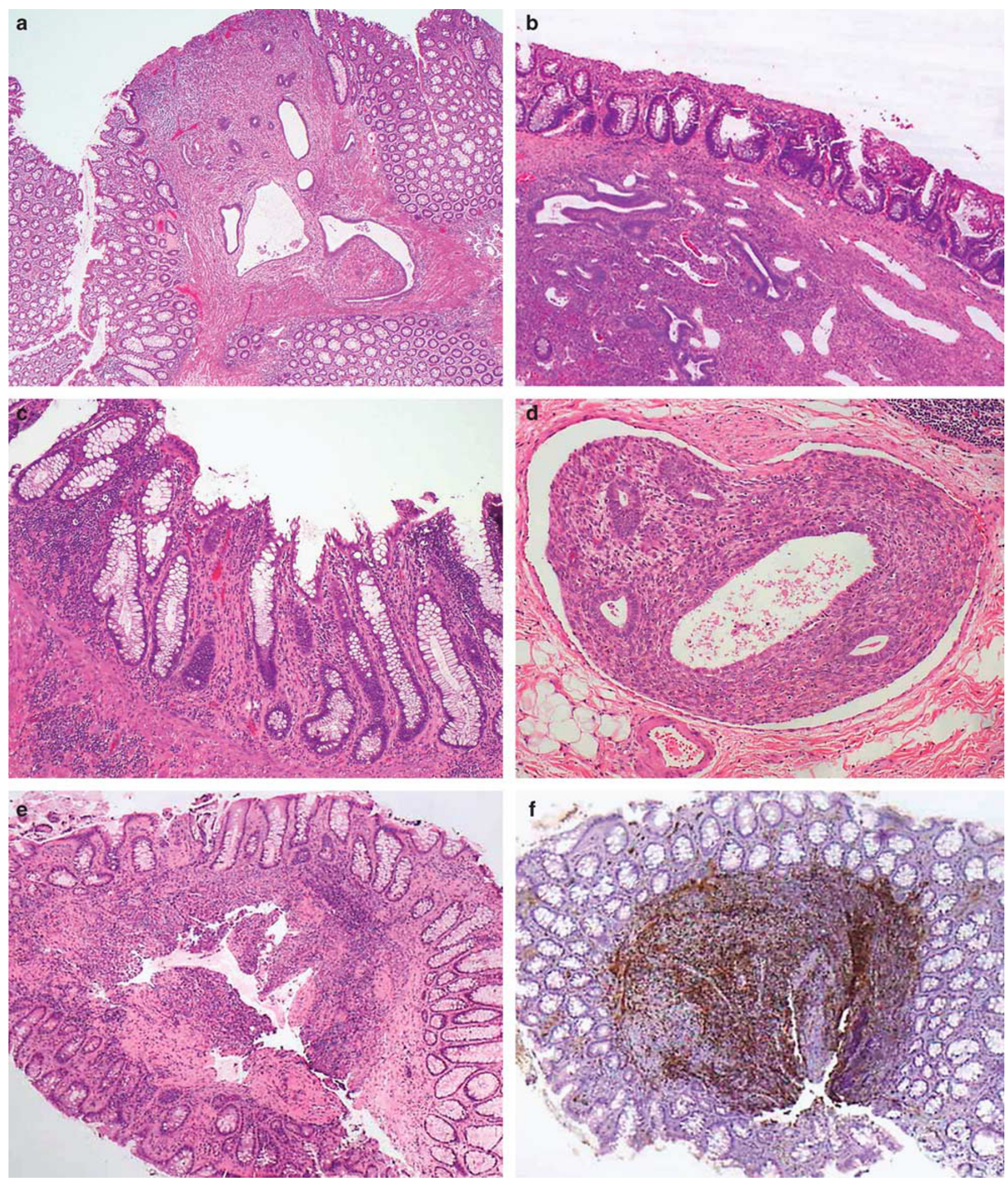

Figure 2 (a) Polypoid endometriosis (H\&E, $20 \times$ ). (b) Crypt architectural distortion caused by underlying endometriosis (H\&E, $100 \times$ ). (c) Prolapse-type changes induced by adjacent mucosal endometriosis (not shown) (H\&E, $200 \times)$. (d) Intravascular endometriosis (H\&E, $200 \times$ ). (e and f) Stromal endometriosis. (e) Cellular spindle cell proliferation in the lamina propria of the colon (H\&E, $20 \times$ ). (f) CK7/ER double staining. The stroma is strongly positive for ER (brown chromogen), but no CK7-positive (red chromogen) glands are present (CK7/ER double immunoperoxidase stain, $20 \times$ ).

malignancy involving both epithelial and stromal components. In our series, two cases showed complex atypical hyperplasia (Figures 3a-c), characterized by increased gland-to-stroma ratio, complex glandular architecture, and cytologic atypia (increased nuclear-to-cytoplasmic ratio, prominent nucleoli, cleared or dense chromatin, and loss of polarity). In addition to endometrial glandular 

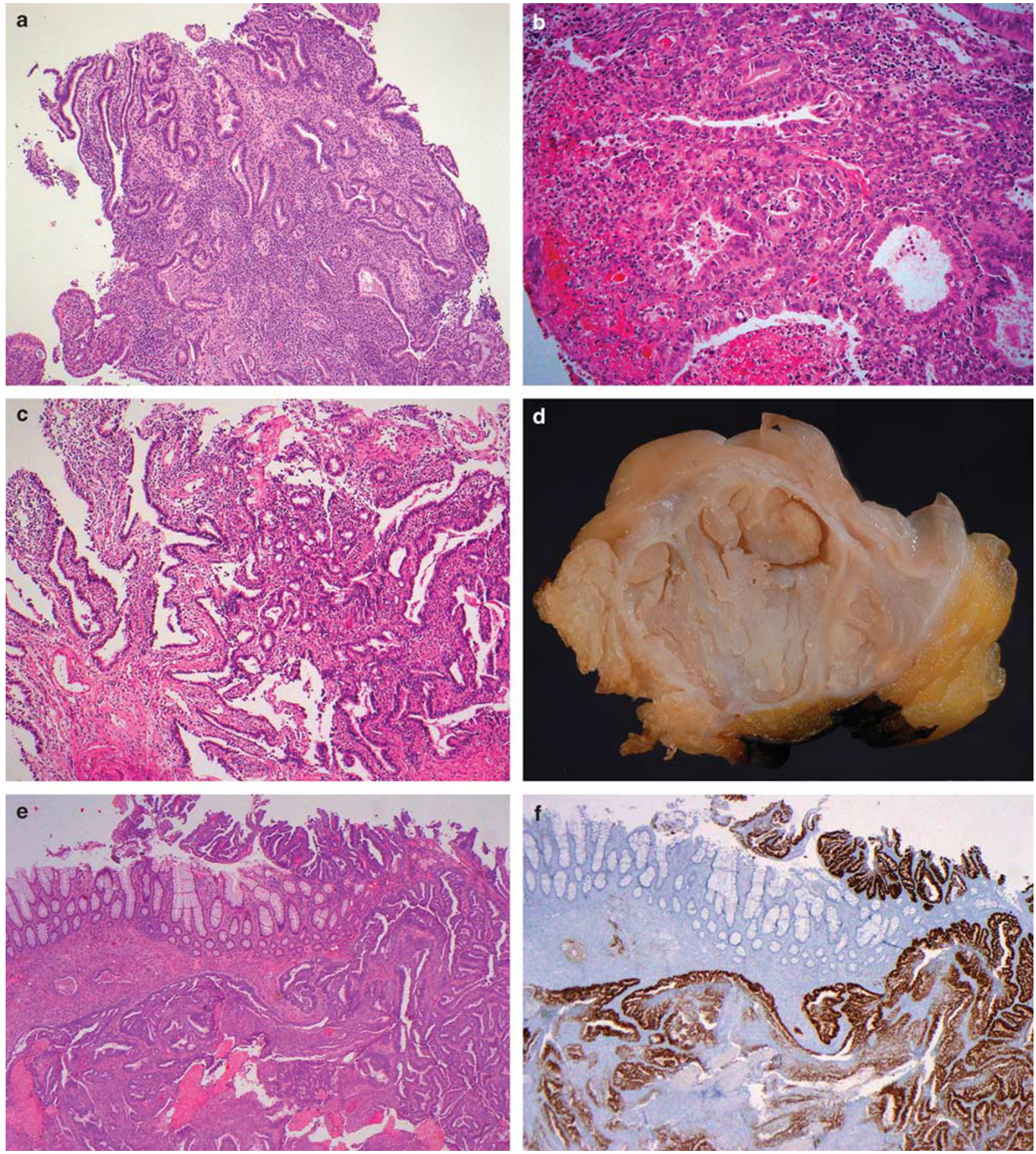

Figure 3 (a and b) Endometriosis with complex atypical hyperplasia in one case (a, H\&E, $40 \times$; b, H\&E, 200 ×). (c) Complex atypical hyperplasia in the second case $(\mathrm{H} \& \mathrm{E}, 100 \times)$. (d-f) Endometrioid adenocarcinoma arising in intestinal endometriosis. (d) Macroscopic image of endometrioid adenocarcinoma. (e) Endometrioid adenocarcinoma extends to involve the mucosa (H\&E, 20 $\times$ ). (f) CK7 highlighted the endometrioid adenocarcinoma glands (immunoperoxidase stain, $20 \times$ ).

hyperplasia, one case also showed concurrent stromal atypia with increased cellularity. Although mitotic activity was rare, a diagnosis of evolving low-grade carcinosarcoma was rendered. Atypical stroma cells were focally present at the deep surgical section margin.
One case demonstrated invasive endometrioid adenocarcinoma arising in endometriosis. Grossly, the tumor was a tan-white circumferential mass measuring $4 \times 3.5 \times 1.6 \mathrm{~cm}$. The bulk of the mass was located within the submucosa, with mucosa and muscularis propria involvement (Figure 3d). 
Microscopically, the tumor was composed of tubular glands or villoglandular structures lined by simple or pseudostratified columnar cells (Figure 3e). Focal squamous differentiation was present. Focal endometrial stroma was noticeable. The tumor cells were strongly positive for CK7 (Figure 3f) and ER (image not shown), but negative for CK20 and CDX2 (images not shown). Fourteen lymph nodes (of 44) were positive for metastasis. All surgical resections were free from tumor.

\section{Clinical Outcome}

Follow-up information was available in all patients, and all were alive at follow-up (3-216 months, mean 67 months). The patient with primary endometrioid adenocarcinoma in the sigmoid colon was treated with megestrol post-operatively, and the patient is alive at 26 months after surgery.

\section{Discussion}

Intestinal mucosal endometriosis is rare, but can cause diagnostic challenges. The lesion can cause severe symptoms, including gastrointestinal bleeding and bowel obstruction. As demonstrated in our series, the clinical impressions included solitary rectal ulcer syndrome/mucosal prolapse, colorectal adenoma, and carcinoma. Endometriosis involving the intestinal mucosa has not been well-studied in the literature. To our knowledge, ours is the largest case series.

Endometriosis of the intestinal tract is usually intramural, and most often does not involve the mucosa and might not be sampled in mucosal biopsies even if it has mucosal involvement. ${ }^{19}$ Occasionally, it can cause mucosal changes that mimic other diseases on histological examination. In our series, about $46 \%$ of mucosal endometriosis showed surface erosion/ulceration, crypt architectural distortion, cryptitis, and crypt abscesses. The changes may raise a possibility of idiopathic inflammatory bowel disease, particularly Crohn's disease, due to the local/segmental involvement of the colon. However, the presence of endometrioid glands and stroma strongly suggest that these colonic mucosa and glandular changes are secondary to endometriosis. In one case in our series, the endometriosis occurred in a patient with well-documented Crohn's disease, indicating that a diagnosis of endometriosis does not completely exclude Crohn's disease, and all clinicopathologic information in each case should be synthesized for the final diagnosis.

Prolapse-type changes including inflammation and fibromuscular hyperplasia within the lamina propria were seen in three cases. For polypoid lesions, these changes can be difficult to distinguish from solitary rectal ulcer syndrome (mucosal prolapse) when endometrial glands are either absent, or scarce. In one of our cases, the biopsy fragment contained only two endometrial glands, and immunostains were needed to confirm their endometrial differentiation.

In our series, the most common indication for biopsy was a polypoid lesion identified on endoscopy. The term 'polypoid endometriosis' was coined by Mostoufizadeh and Scully ${ }^{20}$ in 1980, describing a distinctive variant of endometriosis that simulates an endometrial polyp and may mimic a neoplasm on clinical, intraoperative, and pathologic examination. Further studies have shown that this type of endometriosis occurs over a wide age range, but is more frequent in post-menopausal women, and is associated with hormonal factors. ${ }^{21}$ Seven resected cases in our series showed mass lesions and several were described as polypoid, fitting the definition of 'polypoid endometriosis'. Our data suggest that polypoid endometriosis is a frequent finding in intestinal endometriosis with mucosal involvement.

Like their eutopic counterpart, endometrial glands and stroma can also display metaplastic and hyperplastic changes. In our series, ciliated (tubal) metaplasia was the most common condition, and was a reliable diagnostic clue, as the colorectal glandular epithelium had no cilia. Squamous, eosinophilic, hobnail, and mucinous metaplasia were also present among our cases, although at a lower frequency. The presence of these metaplastic features should prompt a search for typical endometrial glands and its associated stroma. In difficult cases, immunohistochemical stains with a panel of antibodies (CK7, ER, CK20, and CDX2) are helpful. If the biopsy tissue is limited, a dual immunostain for CK7 and ER as described in our study may be used. Hyperplasia and carcinoma can arise from the existing endometriosis, ${ }^{22,23}$ as two cases in our series had complex atypical hyperplasia, one with concurrent stromal atypia with increased cellularity, leading to a diagnosis of an evolving low-grade carcinosarcoma. Atypical stromal cells were present at the surgical resection margin. The patient was treated with hormonal therapy and is alive at 216 months after surgery. Another case was complicated by endometrioid adenocarcinoma, illustrating the malignant potential of these ectopic foci. In this case, the patient had a history of vaginal hysterectomy 25 years prior due to menorrhagia, diagnosed in an outside hospital. However, the diagnosis was not clear and the pathologic material was not available for review. On the basis of the overall morphology, and the long interval between vaginal hysterectomy and the current presentation, this was diagnosed as a primary endometrioid adenocarcinoma arising in endometriosis. This patient was treated with megestrol and is alive at 26 months after surgery. This case illustrates the importance of diagnosing primary endometrioid adenocarcinoma in the intestinal tract, as the treatment after surgery is significantly different, that is, hormonal 
therapy (for endometrioid adenocarcinoma) vs chemotherapy (for colorectal adenocarcinoma).

Endometrial stroma may have a variety of changes including decidua, pseudodecidua, smooth-muscle metaplasia, fibroblastic metaplasia, and sarcoma. ${ }^{18}$ Within the mucosal biopsies, we observed hemosiderin-laden macrophages and extravasated red blood cells as the most frequent findings. Typical cases showed stroma cuffing around the endometrial glands. However, some cases had paucicellular stroma with edematous/myxoid changes at least focally.

Uncommon manifestations of endometriosis include the so-called 'stromal endometriosis'. ${ }^{18}$ One of our biopsy cases contained a spindle cell proliferation within the lamina propria, and a broad differential diagnosis was considered including the common gastrointestinal spindle cell lesions, such as gastrointestinal stromal tumor and benign nerve sheath tumor. Immunohistochemistry using a panel of antibodies (CD10, ER, CD34, CD117, and S-100) is helpful in such cases and would point to the correct diagnosis.

In summary, we report a series of intestinal endometriosis with mucosal involvement, and highlight the importance of having a high index of suspicion when evaluating intestinal biopsies in female patients. Useful morphologic clues to the correct diagnosis of endometriosis are extrinsic/ ectopic endometrioid glands (particularly ciliated epithelium) with or without squamous metaplasia, spindle and cellular stroma, and thickened vessels.

\section{Disclosure/conflict of interest}

The authors declare no conflict of interest.

\section{References}

1 Eskenazi B, Warner ML. Epidemiology of endometriosis. Obstet Gynecol Clin North Am 1997;24:235-258.

2 Weed JC, Ray JE. Endometriosis of the bowel. Obstet Gynecol 1987;69:727-730.

3 Redwine DB. Ovarian endometriosis: a marker for more extensive pelvic and intestinal disease. Fertil Steril 1999;72:310-315.

4 Remorgida V, Ferrero S, Fulcheri E, et al. Bowel endometriosis: presentation, diagnosis, and treatment. Obstet Gynecol Surv 2007;62:461-470.

5 Caselli G, Besa C, Pulgar D. Intestinal obstruction as manifestation of a multifocal colonic endometriosis. Clin Gastroenterol Hepatol 2011;9:e90-e91.

6 De Ceglie A, Bilardi C, Blanchi S, et al. Acute small bowel obstruction caused by endometriosis: a case report and review of the literature. World J Gastroenterol 2008;14:3430-3434.

7 Douglas C, Rotimi O. Extragenital endometriosis-a clinicalpathologic review of a Galsgow hospital experience with case illustrations. J Obstet Gynaecol 2004;24:804-808.

8 Floberg J, Backdahl M, Silfersward C, et al. Postpartum perforation of the colon due to endometriosis. Acta Obstet Gynecol Scand 1984;63:183-184.

9 Garg NK, Bagul NB, Doughan S, et al. Intestinal endometriosis-A rare cause of colonic perforation. World J Gastroenterol 2009;15:612-614.

10 Kanthimathinathan V, Elakkary E, Bleibel W, et al. Endometrioma of the large bowel. Dig Dis Sci 2007;52:767-769.

11 Kratzer GL, Salvati EP. Collective review of endometriosis of the colon. Am J Surg 1955;90:866-869.

12 Kim KJ, Jung SS, Yang SK, et al. Mucosal changes in the large bowel with endometriosis: a possible cause of misdiagnosis of colitis? Hum Pathol 1994;25: 1030-1034.

13 Gupta J, Shepherd NA. Colorectal mass lesions masquerading as chronic inflammatory bowel disease on mucosal biopsy. Histopathol 2003;42:476-481.

14 Daya D, O'Connell G, DeNardi F. Rectal endometriosis mimicking solitary rectal ulcer syndrome. Mod Pathol 1995;8:599-602.

15 Kelly P, McCluggage WG, Gardiner KR, et al. Intestinal endometriosis morphologically mimicking colonic adenocarcinoma. Histopathol 2008;52:510-514.

16 Nasim H, Sikafi D, Nasr A. Sigmoid endometriosis and a diagnostic dilemma-A case report and literature review. Int J Surg Case Rep 2011;2:181-184.

17 Jinushi M, Arakawa A, Matsumoto T, et al. Histopathologic analysis of intestinal endometriosis after laparoscopic low anterior resection. J Minim Invasive Gynecol 2011;18:48-53.

18 Clement PB. The pathology of endometriosis: a survey of the many faces of a common disease emphasizing diagnostic pitfalls and unusual and newly appreciated aspects. Adv Anat Pathol 2007;14:241-260.

19 Yantiss RK, Clement PB, Young RH. Endometriosis of the intestinal tract. A study of 44 cases of a disease that may cause diverse challenges in clinical and pathologic evaluation. Am J Surg Pathol 2001;25:445-454.

20 Mostoufizadeh M, Scully RE. Malignant tumors arising in endometriosis. Clin Obstet Gynecol 1980; 23:951-963.

21 Parker RL, Dadmanesh F, Young RH, et al. Polypoid endometriosis: a clinicopathologic analysis of 24 cases and a review of the literature. Am J Surg Pathol 2004; 28:285-297.

22 Petersen VC, Underwood JC, Wells M, et al. Primary endometrioid adenocarcinoma of the large intestine arising in colorectal endometriosis. Histopathol 2002;40:171-176.

23 Yantiss RK, Clement PB, Young RH. Neoplastic and pre-neoplastic changes in gastrointestinal endometriosis: a study of 17 cases. Am J Surg Pathol 2000;24: 513-524. 